\title{
Monetary Favors and Their Influence on Neural Responses and Revealed Preference
}

\author{
Ann H. Harvey, Ulrich Kirk, George H. Denfield, and P. Read Montague \\ Human Neuroimaging Laboratory, Department of Neuroscience, Computational Psychiatry Unit, Baylor College of Medicine, Houston, Texas 77030
}

\begin{abstract}
Favors from a sender to a receiver are known to bias decisions made by the recipient, especially when the decision relates to the sender, a feature of social exchange known as reciprocity. Using an art-viewing paradigm possessing no objectively correct answer for preferring one piece of art over another, we show that sponsorship of the experiment by a company endows the logo of the company with the capacity to bias revealed preference for art displayed next to the logo. Merely offering to sponsor the experiment similarly endowed the gesturing logo of the company with the capacity to bias revealed preferences. These effects do not depend upon the size of the displayed art or the proximity of the sponsoring logo to the piece of art. We used functional magnetic resonance imaging to show that such monetary favors do not modulate a special collection of brain responses but instead modulate responses in neural networks normally activated by a wide range of preference judgments. The results raise the important possibility that monetary favors bias judgments in domains seemingly unrelated to the favor but nevertheless act in an implicit way through neural networks that underlie normal, ongoing preference judgments.
\end{abstract}

\section{Introduction}

A myriad of laboratory research in social science has shown that individuals are subject to biases in decision-making, ranging in topic from legal scenarios, to job satisfaction, to visual perception (Loewenstein et al., 1993; Brief et al., 1995; Balcetis and Dunning, 2006). Although biases can be self-serving, they may also be rooted in biological mechanisms such as reciprocity that subvert cognitive control. The concept of reciprocity is based on the idea that social gestures from a sender to a receiver encourage some equivalent behavior in return, even if that agreement is not made explicit. One particularly relevant "open-ended" social gesture in this domain is a favor, in which one agent makes a gesture or provides a gift without any explicit expectation of reciprocity. Recent experiments have begun to shed light on the neural mechanisms of reciprocity-eliciting gestures (Rilling et al., 2002; King-Casas et al., 2005; Li et al., 2009; van den Bos et al., 2009); however, almost nothing is known about the influence of an "open-loop" favor in which there is no possibility for reciprocating interactions between the sender and the receiver. This case is particularly important given the real-world evidence that favors can affect medical decision-making (Wazana, 2000; Dana and Loewenstein, 2003) or other fields in which some level of insulation from these biases in judgment is assumed.

To examine the effect of favors on subjective decisionmaking, we designed a task in which web-registered companies sponsored subjects' participation in a decision task in which the choice offered possessed no objectively correct answer and in

Received March 2, 2010; revised May 27, 2010; accepted June 7, 2010.

This work was supported by National Institute of Neurological Disorders and Stroke Grant R01 NS045790, National Institute on Drug Abuse Grant R01 DA11723, and the Kane Foundation. We thank K. Bartley, C. Howard, C. Cortelyou, and C. Bracero for assistance with data collection, M. Ross for programming of experimental design, and N. Apple for the logo design.

Correspondence should be addressed to P. Read Montague, Baylor College of Medicine, 1 Baylor Plaza, S104, Houston, TX77030. E-mail: read@bcm.edu.

DOI:10.1523/JNEUROSCI.1086-10.2010

Copyright $\odot 2010$ the authors $\quad 0270-6474 / 10 / 309597-06 \$ 15.00 / 0$ which there was no natural capacity to "pay the company back." Six separate passive viewing tasks were executed. Each version of the task had two phases: passive art viewing during functional magnetic resonance imaging (fMRI) with no expectation or knowledge of future experimental probes, and out-of-scanner rating of paintings using a standard Likert scale. We chose to use art as our measure of subjective preference because previous experiments have demonstrated that artwork is capable of generating reward-related brain responses, subjects have widely varied preferences for any given painting (Kawabata and Zeki, 2004; Vartanian and Goel, 2004; Kirk et al., 2009), and there is no objectively correct answer for non-art experts (we excluded art experts or art students in this experiment).

We hypothesized that a monetary favor would alter subjects' ability to make valuation judgments, as expressed through their revealed preference for art. Additionally, we predicted that the medial orbitofrontal cortex would be a neural region whose response would be modulated by such a monetary favor. This region of the brain, particularly the ventromedial prefrontal cortex (VMPFC) is widely believed to encode for revealed preference across a variety of sensory modalities (Knutson et al., 2003; O'Doherty et al., 2003; Rolls et al., 2003; McClure et al., 2004; Plassmann et al., 2008; Kirk et al., 2009). Because the fMRI task was passive with no judgments required during scanning, any response modulation in valuation regions would indicate that these regions encode value for the art and also can be modulated by biasing gestures such as monetary favors even before subjects are asked to make a decision regarding their preference.

\section{Materials and Methods}

Participants. A total of 151 subjects participated in the study. All subjects gave informed consent to participate in the experiments, and the Baylor Institutional Review Board approved the experimental paradigms.

Procedure for the branded favor experiment (task 1). Before scanning, subjects were told they would be sponsored for their participation by one of two companies. Three groups of subjects participated in the task and 
were paid $\$ 30(n=29), \$ 100(n=29)$, or $\$ 300(n=29)$ depending on the condition. At the beginning of the fMRI task (Fig. $1 A$ ), subjects saw two company logos, followed by a screen indicating which of the two companies would be sponsoring them, as well as their amount of compensation. Subjects passively viewed 60 reproductions of paintings, each one paired with either a sponsor logo or a non-sponsor logo, while undergoing fMRI scanning. Images were displayed on a backprojected computer screen that subjects viewed with a mirror above their eyes in the scanner. Subjects were instructed to merely look at the screens while the paintings/logos were displayed. Each painting/logo pairing was displayed for $5 \mathrm{~s}$, with a dark blank screen shown between paintings for a duration of 4-14 s. The order of paintings was varied for each subject, as were the painting/logo pairings. Each subject saw two of four possible logos, with each combination of logos distributed evenly across the subject population (12 possible logo sets). The logo chosen to be the sponsor was randomly assigned for every subject, with the alternate logo chosen as the non-sponsor logo. For the $\$ 30$ condition, there was a slight variation in which some paintings were paired with a box that said "No Logo." After collecting the initial dataset, we removed the "No Logo" condition and the remaining tasks were done with only the "sponsor" and "nonsponsor" conditions. This was done in an effort to visually balance all stimuli presented in the session.

After scanning, subjects were asked to participate in a behavioral session in which they rated each of the paintings (paired with the same logos as in the scanner) based on how much they liked each of the paintings on a scale of -4 (dislike) to +4 (like). The behavioral session took place outside of the MRI scanner at a desktop computer. Responses were logged using the computer keyboard. Before scanning, subjects were told they would be participating in a second behavioral session, but they were not told before scanning that they would be rating the paintings. They were also explicitly told that the number of times they saw either logo or the ratings they provided would in no way affect their compensation. During passive viewing, each of the 60 paintings was paired with either the sponsor logo or another, non-sponsor logo. All logos were unfamiliar to the subjects in that logos were prefabricated by the experimenters. In the behavioral task, the paintings were displayed in a randomized order compared with the scanner portion, but the painting/logo pairings were kept consistent across both tasks. Each subject also filled out a postscan questionnaire in which they were asked to rank the two logos they saw during the experiment among a group of seven logos.

Procedure for the spatial favor experiment (task 2). The procedure for the second task differed from task 1 with regards to the following factors. A new set of stimuli composed of 90 abstract paintings was applied. Furthermore, the size of the paintings was decreased to occupy $\sim 5 \%$ of visual angle. The paintings were displayed centrally on the screen, with the logos presented at two different positions on both sides of the screen. The positioning of the logos acted as a free parameter on the horizontal axis and was displayed in one condition next to the painting (with a distance between painting and logo at $1 \%$ visual angle) and at the side of the visual display in the other condition (the distance between painting and logo in this condition occupied $10 \%$ of visual angle). The task was performed on the $\$ 300$ version $(n=19)$. The procedure for task $2 \mathrm{mim}$ icked the original task, as detailed above.

Procedure for the mere-offer experiments. For the "mere-offer" experiments, the procedure was similar to the original design, with modifications to the introductory screens. In version 1 ( $n=21$ subjects), both companies offer to sponsor and the computer chooses which company will follow through with the offer. In version $2(n=$ 24 subjects), one company offers and the computer randomly chooses whether or not the company will follow through with the offer. Only the cases in which the computer chose to reject the offer of the company are included in the analysis. In this condition, subjects still received $\$ 300$ but not from the company.

Image acquisition. The anatomical and functional imaging was performed using 3 tesla Siemens Allegra and Siemens Trio scanners. High-resolution T1-weighted scans were acquired using an magnetization-prepared rapidacquisition gradient echo sequence with $1 \mathrm{~mm}$ resolution. For functional imaging, whole-brain echo planar images were acquired with blood oxygenation level-dependent (BOLD) contrast and a repetition time of $2000 \mathrm{~ms}$ (echo time, $40 \mathrm{~ms}$; flip angle, $90^{\circ}$, aligned to anterior/posterior commissure). Slice acquisition was interleaved, comprising $264 \mathrm{~mm}$ axial slices, yielding $3.4 \times 3.4 \times 4.0 \mathrm{~mm}$ voxels.

Image analysis. Analysis of fMRI data was performed using SPM2 (Friston et al., 1995). Data were realigned, corrected for slice timing artifacts, and normalized to a canonical spatial axis, and the resulting images were smoothed with a Gaussian kernel ( $8 \mathrm{~mm}$ full-width halfmaximal). An event-related, random effects model was applied; events were modeled as $5 \mathrm{~s}$ boxcars at the onset of each image presentation. Each subjects' behaviorally expressed preference for the paintings was used as a linear covariate of the painting presentation. Regions of interest (ROIs) were determined using the statistical maps for the random effects analysis unless otherwise noted. Data were displayed using the xjView toolbox.

\section{Results}

\section{Effect of sponsorship on expressed preference for art}

We wanted to determine whether the monetary favor biased the subjects' report of painting preference and whether the monetary amplitude of sponsorship had an effect on this bias. Here, the question is whether a general favor (sponsoring the experiment) can bias a preference judgment along some unrelated dimension. In this setup, there is no natural way for subjects to "pay back" the sponsoring company. Other than visual juxtaposition, there was no explicit association between the painting and the company logos.

To explore this hypothesis, we initially paid subjects $\$ 30$. To look for increasing effects of the influence of the gesture on preference behavior, we ran two additional cohorts at $\$ 100$ and $\$ 300$. There was a trend toward preferring paintings next to the logo of a sponsoring company in the $\$ 30$ and $\$ 100$ conditions (supplementary data $\mathrm{S1}$, available at www.jneurosci.org as supplemental material), but there was only a significant effect of sponsorship on art preference at $\$ 300$ (Fig. $1 B$ ). Moreover, the effect of the sponsorship on preference was also mirrored in the subjects' behavioral ranking of the logos (Fig. 1C). Sponsorship was counterbalanced across all possible logo combinations (two logos per experiment); therefore, this result is based solely on sponsorship differences and does not rely on variables intrinsic to the appeal (or not) of either the logos or paintings. Because there was a significant behavioral effect at $\$ 300$, we primarily focus the remaining results and follow-up experiments on this level of monetary favor.

\section{Neural responses correlated with sponsorship effect}

In the brain imaging data, we sought to identify BOLD signals present during the passive viewing paradigm that correlated with the behavioral effect of the monetary favor of the sponsor on expressed preference for paintings paired with the sponsor logo. We hypothesized that the VMPFC, which correlates with preference for varied stimuli, would similarly encode differences in preference for sponsor compared with non-sponsor paintings. Activity in this region correlated linearly with painting preference in the $\$ 300$ task when collapsed across sponsorship (Fig. $2 \mathrm{~A}$, top) $(p<0.001)$. To look at the effect of sponsorship in this region, we constructed an ROI in the VMPFC centered on the midline with Montreal Neurological Institute coordinates [0, 48, - 16] constituting 33 voxels (Fig. $2 \mathrm{~A}$, bottom). This ROI overlaps with activity reported in a previous study of the effects of wine price on taste preference (Plassmann et al., 2008). The percentage signal change for sponsor paintings was significantly higher than for nonsponsor paintings $\left({ }^{*} p<0.05\right)$. It was possible that the VMPFC response was secondary to a stronger response in regions that may be influenced to a significant degree by sponsorship. However, in a contrast of sponsor $>$ non-sponsor regardless of preference, responses for the $\$ 300$ condition showed no significant 
A
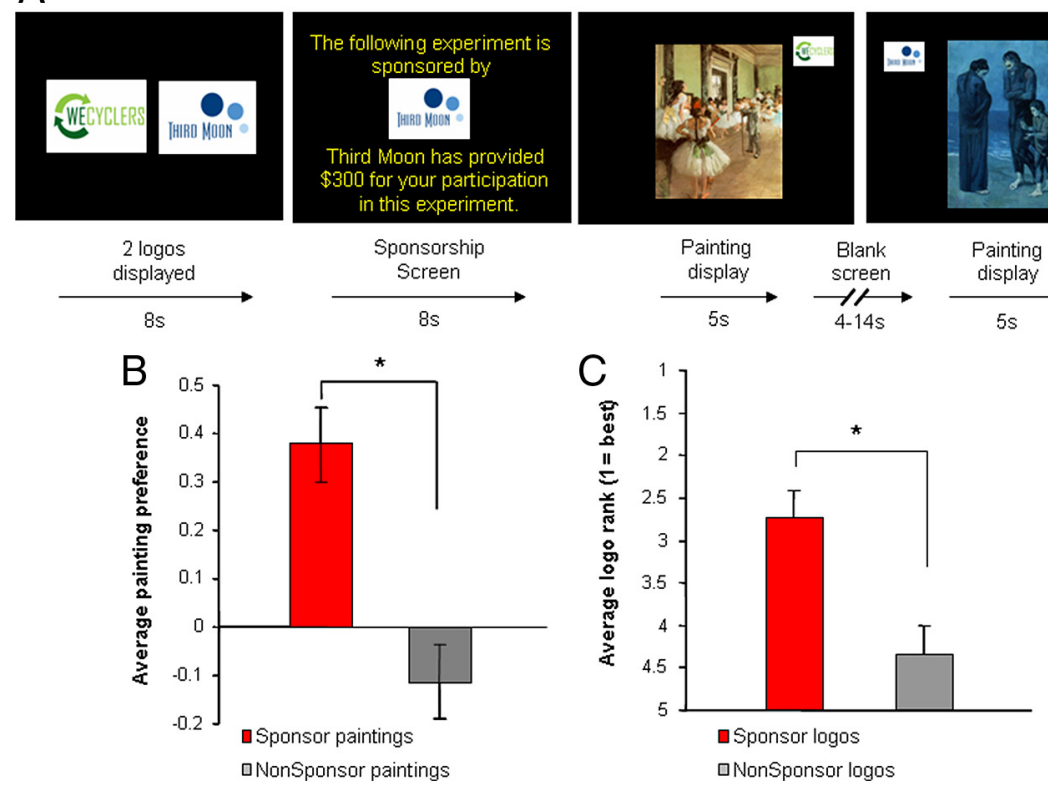

Figure 1. Experimental design and behavioral results. $A$, Timing of the scanning experiment. Subjects were told that one of the companies (represented by the logos) would be contributing to funds they would receive for compensation in the experiment. During the scanning task, subjects were instructed to merely look at the screens while the paintings/logos were displayed. Sixty paintings were displayed during the scanning session; each painting was shown once, paired with either a sponsor logo or a non-sponsor logo. After scanning, subjects also rated how much they liked each of the paintings ( -4 to +4 Likert scale) and ranked their preference for the logos among a group of seven unfamiliar logos. $\boldsymbol{B}$, In the behavioral session, subjects preferred paintings paired with sponsor logos $\left({ }^{*} p<0.002\right)$. C, Subjects preferred sponsor logos compared with non-sponsor logos in a postscan questionnaire $\left(^{*} p<0.002\right)$.
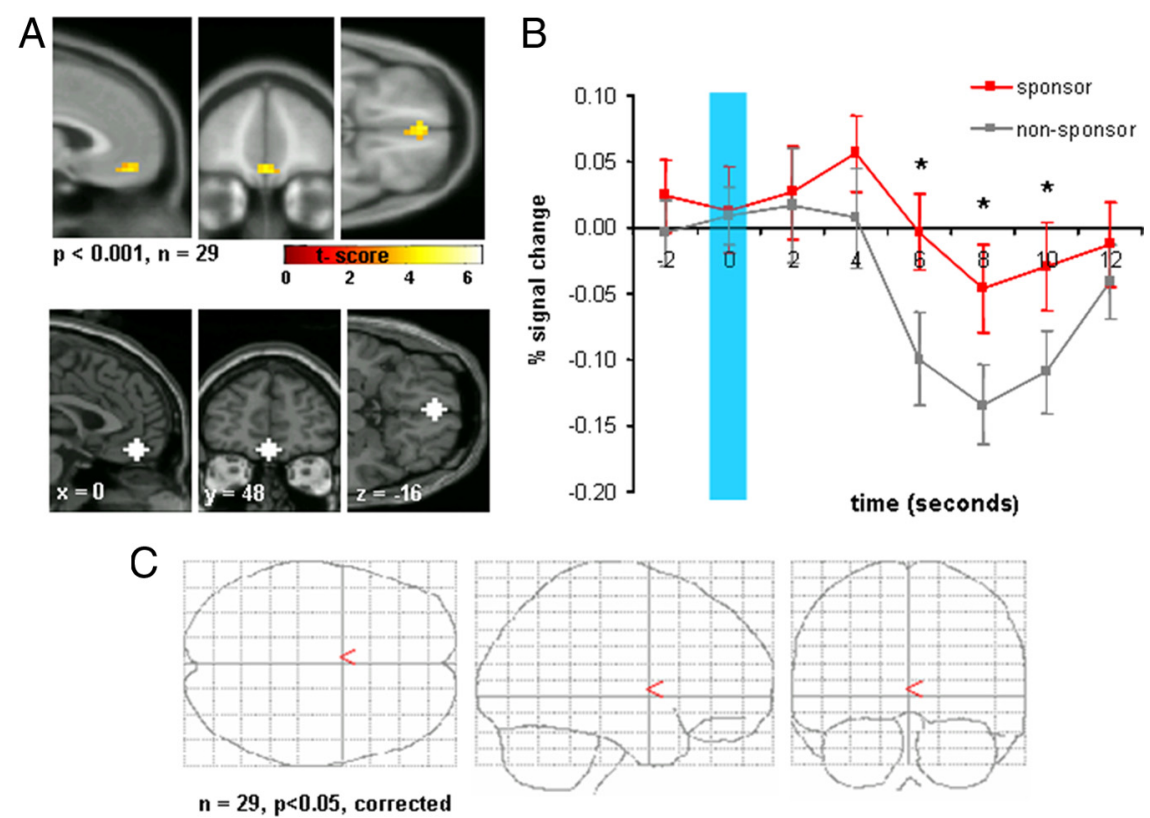

Figure 2. Neural responses for sponsorship effect. $\boldsymbol{A}$, Top, VMPFC response increases linearly with preference rating ( $p<$ 0.001 , uncorrected), MNI $[4,50,-16]$. Bottom, Region of interest in VMPFC. $\boldsymbol{B}$, Time series showing that percentage signal change in VMPFC is higher for sponsor than non-sponsor paintings in the defined ROI (blue box denotes onset of painting). ${ }^{*} p<0.05$. C, No regions were found in the GLM for the contrast sponsor paintings $>$ non-sponsor paintings ( $p<0.05$, FDR corrected).

difference in BOLD activity in any brain regions (Fig. $2 C)[n=$ $29, p<0.05$, false discovery rate (FDR) corrected for multiple comparisons]. This result held even when combining all monetary conditions to look for any global responses to sponsor paintings $>$ non-sponsor paintings across all 87 subjects in the $\$ 30$,
$\$ 100$, and $\$ 300$ tasks (supplemental data S1, available at www.jneurosci.org as supplemental material). Such negative conclusions should be tempered by the fact that there remain no good estimates of false-negative rates in BOLD imaging experiments; nevertheless, with 87 subjects, the total lack of response for this contrast is at least strongly suggestive that there is no "global sponsorship effect." The lack of a global sponsorship effect and the activity found in the hypothesized region of the VMPFC suggested the hypothesis that the neural networks normally activated by a wide range of preference judgments were being modulated by the robust effect of sponsorship.

To test this hypothesis, we built a regressor using each subject's reported preference for each painting to identify brain responses whose activity linearly covaried with subjective preference. When all monetary conditions were collapsed, significant correlations were found bilaterally in the parahippocampal gyrus, precuneus, and middle temporal gyrus near the junction with the occipital poles (Fig. $3 A)(n=87$, displayed at $p<10^{-6}$ uncorrected). The regions displayed survived a more stringent, FDR-corrected threshold at $p<10^{-5}$. The brain regions found using the subjective preference regressor were used to generate regions of interest for additional analysis. These regions linearly correlated with preference even when excluding the $\$ 300$ data from the general linear model (GLM) analysis (supplemental data S2, available at www.jneurosci.org as supplemental material). Given the interaction of sponsorship and painting preference in the $\$ 300$ condition, we expected that there might be an effect of the sponsorship on those regions found to encode the revealed preference of the paintings for each subject. The percentage signal change was higher for sponsor paintings than nonsponsor paintings in the middle temporal gyrus (Fig. 3B, left) $(p<0.05)$ and parahippocampal gyrus (Fig. $3 B$, middle) $(p<0.05)$ but did not reach significance for the precuneus (Fig. 3B, right).

It was entirely possible that the relative logo size or proximity to the painting contributed to the observed neural and behavioral effects. To test this hypothesis directly, we performed a separate experiment ( $n=19$ subjects) in which the size of the painting was reduced relative to the logo size (they were approximately equal sized) and in which the distance from logo to painting acted as a free parameter (supplementary data $\mathrm{S} 3 \mathrm{~A}$, available at www.jneurosci.org as supplemental material). We used 90 abstract paintings that did not overlap with the original set of paintings in the first task. In this setup, we 
reproduced the effect of the sponsoring logo on preference using the reduced-size paintings (examining only the $\$ 300$ condition) (supplemental data $\mathrm{S} 3 B$, available at www.jneurosci.org as supplemental material), but there was no effect of logo distance. Together with the above results, this experiment suggested that the sponsorship effect is robust and not sensitive to changes such as relative logo size or distance from the stimuli.

\section{Value of a "mere offer" of a favor}

In the experiments so far described, the sponsoring company made a monetary offer to pay for the experiment and followed through with the offer, whereas the other company made no offer. In follow-up tasks, we asked the question what if an offer is made but not executed? Is there a mere-offer effect similarly transferred to the logo? Perhaps the mere intention to pay for an experiment builds in a subject's mind a kind of "warm glow" associated with the company logo that made the offer whether or not the offer was honored. Based on this hypothesis, we designed two additional tasks to examine the possibility that the mere offer of a favor could be enough to bias the subjects' subjective preference for paintings, even in the absence of actual compensation from the offering company.

In the first mere-offer experiment ( $n=21$ subjects), both companies offered to sponsor the subjects' participation in the experiment for $\$ 300$, and the computer randomly selected which company sponsored the experiment (Fig. $4 A$ ). In the second version of the mere-offer experiment ( $n=24$ subjects), one company offered to pay and the computer randomly selected whether or not the company sponsors the experiment (Fig. $4 B$ ). In the case in which the computer chose for the company not to sponsor the subject, subjects were still compensated $\$ 300$ through our normal route of payment. After the introductory screens, the task was identical to the original branded favor experiment (for fullscreen displays, see supplemental data S4, available at www. jneurosci.org as supplemental material). Only cases in which the subjects were not paid by the offering company were included in the analysis. Therefore, in both versions of the task, there was a company that merely offered to sponsor the subject for $\$ 300$, without the subject receiving money from the offering company. The goal was to compare the effect of a mere offer to the case from the previous experiment in which the non-sponsoring company does not make an offer of a monetary favor to subjects. The question asked by these two experiments is straightforward: if subjects assign the least value to paintings associated with the non-sponsoring company logo, does their value increase when the company merely offers to do them a favor? In all cases, none of the companies paid the subject, so this manipulation allowed us to evaluate the value of a favor while controlling for monetary compensation.

The behavioral results show that the value of the mere offer depends on two factors: (1) whether an offer of a favor is made, and (2) whether there is a competing offer (Fig. 4C). Based on the average preference ratings of the paintings in the three tasks, subjects assigned the least value to the logo of the company that
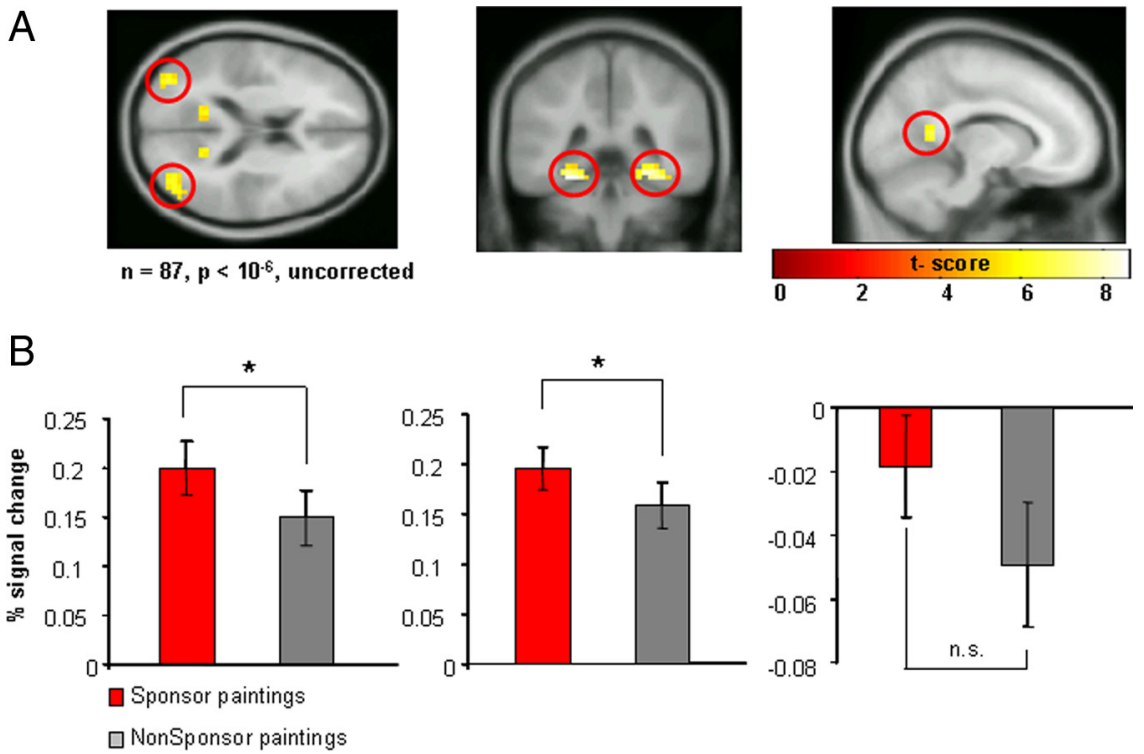

Figure 3. Neural activity related to painting preference and effect of sponsorship. $\boldsymbol{A}$, Neural activity during passive art viewing that covaried with subjects' individual preferences was found in the bilateral temporal-occipital junction $[38,-75,15]$, the Percentage signal change showing effect of sponsorship on brain regions correlated with preference responses in the $\$ 300$ task. Middle temporal-occipital and parahippocampal regions were significantly more active for sponsor paintings $\left({ }^{*} p<0.05\right)$.

did not offer a favor, when the other company sponsored them. This is reflected in the lowest ratings for paintings associated with these non-sponsoring logos. The painting preference is intermediate when the company merely offers but the other company paid them. However, painting preference is significantly higher when paired with a company that merely offers to do the favor when the opposing company did not pay the subject for participation. The results from this manipulation suggest that, even when an agent does not follow through with the monetary compensation, the mere offer of a favor carries value that is capable of influencing subjective decision-making. Neural responses in the medial prefrontal cortex and the posterior cingulate correlated linearly with the behavioral change in preference across the three offer conditions (Fig. $4 D)(p<0.005$, uncorrected). The region of the medial prefrontal cortex, specifically the para-anterior cingulate cortex, has been shown previously to be activated by both social and nonsocial rewarding stimuli (Rilling et al., 2002; Nieuwenhuis et al., 2005; van den Bos et al., 2007).

\section{Discussion}

The studies were designed to test the effect of monetary favors on subjective decision-making. We hypothesized that a monetary gesture from a sponsoring company would alter preference judgments related to the favor and, based on previous studies of preference responses for a wide range of stimuli, that the VMPFC would be modulated by changes in expressed preference induced by the favor (Knutson et al., 2003; O’Doherty et al., 2003; Rolls et al., 2003; McClure et al., 2004; Plassmann et al., 2008; Kirk et al., 2009). A monetary favor from a company was indeed capable of robustly influencing preference for art paired with the logo of the sponsoring company logo. This bias was present despite the fact that subjects were unfamiliar with the company logos, subjects had no reciprocal interaction with the company, and the only association between the art and the sponsoring company was visual juxtaposition on a computer screen. To our knowledge, this is the first neuroimaging study to test the biasing effects of a monetary favor on expressed preference. The imaging results of 
A

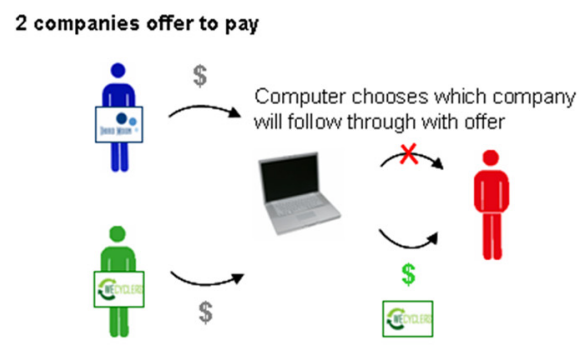

B

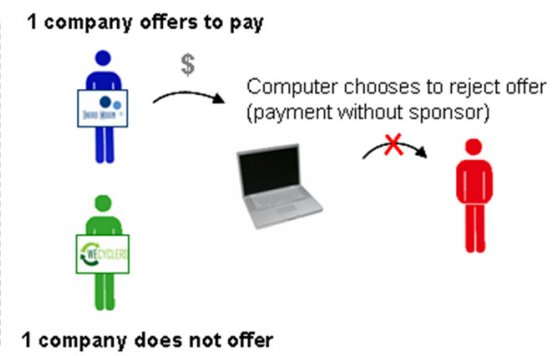

C

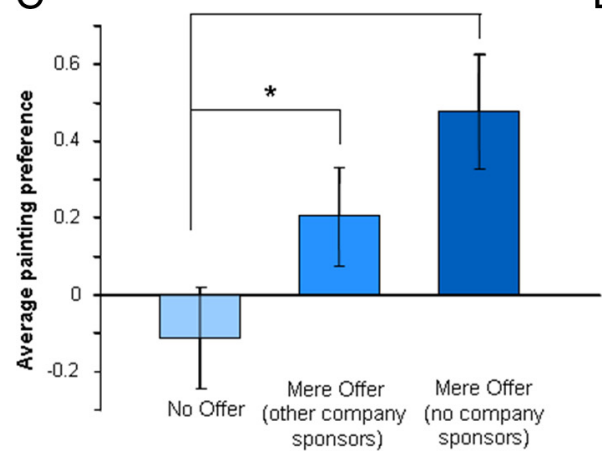

D
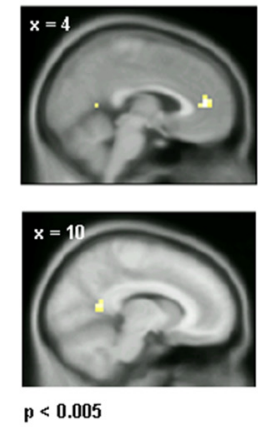

Figure 4. Experimental design for mere-offer experiments and behavior/imaging results. $\boldsymbol{A}$, In group 1 ( $n=21$ ), both companies offered to pay the subject, and the computer randomly selected which of the two companies sponsored the subject's participation. $\boldsymbol{B}$, In group 2 ( $n=24)$, one company offered to sponsor their participation in the experiment. The computer randomly selected whether they received their compensation from the company or through our normal route of compensation (without sponsorship). Only the subjects in which the computer selected payment without sponsor were included in the analysis. After the introductory screens, the experiment proceeded as the original task, with paintings being displayed paired with either the mere-offer company logo or the other company logo. $\boldsymbol{C}$, The mere offer of a favor increases the behaviorally expressed preference for paintings compared with a company that makes no offer. The average painting preference is lowest for the no-offer condition (original branded favor task), intermediate for the mere-offer condition in group $1(\boldsymbol{A})$, and highest for the mere-offer condition in group $2(\boldsymbol{B}) .{ }^{*} p=0.05,{ }^{* *} p=0.002$. $\boldsymbol{D}$, Neural responses in medial prefrontal cortex and posterior cingulate increase linearly with value of mere offer $(p<0.005$, uncorrected).

the first experiment showed that the VMPFC was differentially activated for sponsor and non-sponsor paintings, consistent with the hypothesis that the VMPFC not only encodes preference for passively presented artwork but that it can be modulated by social gestures that influence value judgments even before the actual preference-based decision. Based on these results, we also showed that other regions that encode preference for paintings, including the middle temporal-occipital region and parahippocampal gyrus, are similarly modulated by sponsorship. These regions have been found to be activated by item recognition, object identity, associative memory, and acquisition of conceptual knowledge (Yonelinas et al., 2001; Kumaran et al., 2009), suggesting that strengthened associations between the paintings and logos or increased memory for sponsor paintings may be a mechanism that explain the increased preference.

In the spatial favor task, we altered the design of the stimuli so that the logos could be presented at different distances from the painting. This allowed us to examine the effect with a separate set of paintings displayed at a smaller size while also testing the influence of the influence of the logo at varying distances from the painting. The favor consistently altered preference responses for sponsored paintings in this experiment, but we found no effect of relative distance between the logo and the painting.

Behavioral questionnaires were completed by subjects after the experiments. We asked subjects explicitly if they felt that the presence of the logo influenced their ability to judge the paintings, and none reported any potential influence. This suggests that the ob-
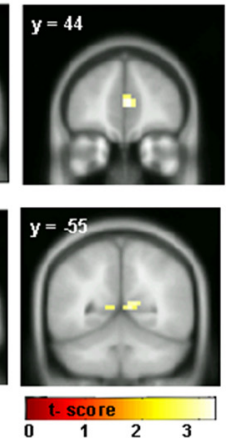

served influence is covert and that subjects are not consciously changing their judgment. This finding is consistent with the lack of "global sponsorship" effect in the neural data. Rather, the influence of the gesture by the sponsor seems to be encoded in regions already known to be correlated with valuation decisions along other dimensions. It is an open question whether top-down cognitive control could be exerted to mitigate the effects of the sponsorship in a manner similar to how people are capable of regulating emotional responses (Delgado et al., 2008).

The behavioral effects seen in this experiment are similar to a phenomenon in the psychology literature known as the halo effect. In the halo effect, global evaluations of an object (usually a person) can induce changes in judgments of attributes of the person (Nisbett and Wilson, 1977). Although our experiments did not involve evaluation of people and personal attributes, it is worth noting similarities in our behavioral results and the halo effect. In agreement with studies of the halo effect, our results suggest that there is an implicit "global evaluation" of the sponsoring company that not only affects the specific attributes of the company (the logo preference) but also transfers positive attributes to nearby paintings.

Although our current work fits in with the framework of the halo effect, the attributes that changed the preference responses for the paintings were unrelated to the paintings themselves. The change in preference for the logos is consistent with the idea that a gesture from the company would change evaluation of decisions about the company, including how much subjects like the logo. Our results extend the effect by demonstrating that a social gesture can be transferred to a stimulus such as a brand and that the traits of this entity (the gesturing company) can be transferred to another stimulus by mere proximity.

The final set of experiments demonstrated that even the mere offer of a favor is capable of positively influencing preference judgments. The strength of the effect depended on whether an offer was extended by the company as well as the context of the gesture. Subjects assigned the most value to offers from companies when the other company did not sponsor them and the least value to companies that made no offer at all (in which the other company sponsored them). We did not find modulated activity in the same area of the VMPFC but a nearby region of the medial prefrontal cortex referred to as the para-anterior cingulate cortex. Although not identical to the previously identified VMPFC, this region has been found to be modulated by both social and nonsocial rewarding stimuli (Rilling et al., 2002; Nieuwenhuis et al., 2005; van den Bos et al., 2007). The difference in localization of activity may be attributable to the fact that this contrast is comparing offers in which there was no difference in monetary value. The difference between the offers was exclusively a manipulation of the value of the social gesture, because the mere offer did not come with any actual monetary payout. This result fits well with the idea that the region of the medial prefrontal cortex extending 
into the rostral anterior cingulate may encode the social context in addition to the acquired reward (Rushworth et al., 2007).

An important feature of these tasks is that subjects passively viewed paintings while in the scanner and were not asked to rate the paintings, nor were they told about the ratings. Instead, subjects were asked after the passive viewing session to rate the paintings outside the scanner. This design removes the possibility of confusing brain activations related to motor or premotor activity with valuation-dependent responses, and it eliminates the possibility of brain responses attributable to prospective encoding in which subjects start deciding how much they prefer a painting during the passive picture presentation. The real-world analog would be visiting a museum for pleasure or visiting a museum knowing that you would later be asked to assign preferences to the paintings you saw.

By passively presenting paintings, we were able to explore implicit valuation responses separate from explicit decisionmaking. In a recent study by Lebreton et al. (2009), the authors showed that subjects were capable of generating value responses even when distracted by other tasks. The results of the Lebreton et al. study provide corroborative evidence for the brain computing value for objects without explicitly asking for preference judgments, specifically in valuation regions, including the ventral striatum and the VMPFC. These results raise an important question about the nature of the value signal during our paradigm. Does the value signal get computed as the painting and logo are passively viewed? Our results would suggest that the answer is yes because there was no impending decision to make and no explicit incentive for subjects to consciously value the painting. This interpretation would be most consistent with the idea that the value signal is being computed online before any choice is made (Plassmann et al., 2008; Kirk et al., 2009).

In summary, these findings show that monetary favors and even the mere offer of a monetary favor bias judgments in domains seemingly unrelated to the favor but nevertheless act in an implicit way through neural networks that underlie normal, ongoing preference judgments. The fact that the neural correlates of the observed behavioral effects did not show any special "sponsorship modulated region" but instead took advantage of responses that would come online for a range of preference judgments suggests that these effects may in large part be implicit and difficult to detect consciously.

These results also have implications for the assessment of conflict of interest. Physicians and the pharmaceutical industry, for instance, are under increasing scrutiny for the mounting evidence that gifts to physicians are capable of drastically influencing treatment and prescribing behavior. In reports collating physician attitudes about gifts from the pharmaceutical industry, physicians often deny that gifts could influence their prescribing behavior, and yet receiving gifts have been found to result in increased prescribing of the drug of the company (Wazana, 2000). In our experiment, we show that monetary favors only mildly associated with the stimuli being judged could still influence behavior, suggesting that repeated reciprocal interactions with a company providing gifts could easily influence physicians' valuation mechanisms without their explicit knowledge.

\section{References}

Balcetis E, Dunning D (2006) See what you want to see: motivational influences on visual perception. J Pers Soc Psychol 91:612-625.

Brief A, Butcher A, Roberson L (1995) Cookies, disposition, and job attitudes: the effects of positive mood-inducing events and negative affectivity on job satisfaction in a field experiment. Organ Behav Hum Dec Process 62:55-62.

Dana J, Loewenstein G (2003) A social science perspective on gifts to physicians from industry. JAMA 290:252-255.

Delgado MR, Gillis MM, Phelps EA (2008) Regulating the expectation of reward via cognitive strategies. Nat Neurosci 11:880-881.

Friston KJ, Ashburner J, Frith C, Poline JB, Heather JD, Frackowiak RS (1995) Spatial registration and normalization of images. Hum Brain Mapp 2:165-189.

Kawabata H, Zeki S (2004) Neural correlates of beauty. J Neurophysiol 91:1699-1705.

King-Casas B, Tomlin D, Anen C, Camerer CF, Quartz SR, Montague PR (2005) Getting to know you: reputation and trust in a two-person economic exchange. Science 308:78-83.

Kirk U, Skov M, Hulme O, Christensen MS, Zeki S (2009) Modulation of aesthetic value by semantic context: an fMRI study. Neuroimage 44:1125-1132.

Knutson B, Fong GW, Bennett SM, Adams CM, Hommer D (2003) A region of mesial prefrontal cortex tracks monetarily rewarding outcomes: characterization with rapid event-related fMRI. Neuroimage 18:263-272.

Kumaran D, Summerfield JJ, Hassabis D, Maguire EA (2009) Tracking the emergence of conceptual knowledge during human decision making. Neuron 63:889-901.

Lebreton M, Jorge S, Michel V, Thirion B, Pessiglione M (2009) An automatic valuation system in the human brain: evidence from functional neuroimaging. Neuron 64:431-439.

Li J, Xiao E, Houser D, Montague PR (2009) Neural responses to sanction threats in two-party economic exchange. Proc Natl Acad Sci U S A 106:16835-16840.

Loewenstein G, Issacharoff S, Camerer C, Babcock L (1993) Self-serving assessments of fairness and pretrial bargaining. J Legal Stud 22:135-159.

McClure SM, Li J, Tomlin D, Cypert KS, Montague LM, Montague PR (2004) Neural correlates of behavioral preference for culturally familiar drinks. Neuron 44:379-387.

Nieuwenhuis S, Slagter HA, von Geusau NJ, Heslenfeld DJ, Holroyd CB (2005) Knowing good from bad: differential activation of human cortical areas by positive and negative outcomes. Eur J Neurosci 21:3161-3168.

Nisbett RE, Wilson TD (1977) The halo effect: evidence for unconscious alteration of judgments. J Pers Soc Psychol 35:250-256.

O'Doherty J, Winston J, Critchley H, Perrett D, Burt DM, Dolan RJ (2003) Beauty in a smile: the role of medial orbitofrontal cortex in facial attractiveness. Neuropsychologia 41:147-155.

Plassmann H, O'Doherty J, Shiv B, Rangel A (2008) Marketing actions can modulate neural representations of experienced pleasantness. Proc Natl Acad Sci U S A 105:1050-1054.

Rilling J, Gutman D, Zeh T, Pagnoni G, Berns G, Kilts C (2002) A neural basis for social cooperation. Neuron 35:395-405.

Rolls ET, Kringelbach ML, de Araujo IE (2003) Different representations of pleasant and unpleasant odours in the human brain. Eur J Neurosci 18:695-703.

Rushworth MF, Buckley MJ, Behrens TE, Walton ME, Bannerman DM (2007) Functional organization of the medial frontal cortex. Curr Opin Neurobiol 17:220-227.

van den Bos W, McClure SM, Harris LT, Fiske ST, Cohen JD (2007) Dissociating affective evaluation and social cognitive processes in the ventral medial prefrontal cortex. Cogn Affect Behav Neurosci 7:337-346.

van den Bos W, van Dijk E, Westenberg M, Rombouts SA, Crone EA (2009) What motivates repayment? Neural correlates of reciprocity in the Trust Game. Soc Cogn Affect Neurosci 4:294-304.

Vartanian O, Goel V (2004) Neuroanatomical correlates of aesthetic preference for paintings. Neuroreport 15:893-897.

Wazana A (2000) Physicians and the pharmaceutical industry: is a gift ever just a gift? JAMA 283:373-380.

Yonelinas AP, Hopfinger JB, Buonocore MH, Kroll NE, Baynes K (2001) Hippocampal, parahippocampal and occipital-temporal contributions to associative and item recognition memory: an fMRI study. Neuroreport 12:359-363. 